\title{
Performance of Noninvasive Ventilation Masks in a Lung Model of COPD Exacerbation
}

\author{
Bruno Rocha de Macedo, Francinni Mambrini Pires Rego, Fabia Diniz Silva, \\ Juliana Valerio Pinaffi, and Juliana Carvalho Ferreira
}

\begin{abstract}
BACKGROUND: Noninvasive ventilation (NIV) reduces intubation and mortality in patients with COPD exacerbation who present with respiratory failure, and the type of mask may affect its success. Our objective was to compare the performance of 3 different NIV masks in a lung model. METHODS: We set the lung simulator mechanics and respiratory rate, and tested a small oronasal mask, a total face mask, and a large oronasal mask. We added $\mathrm{CO}_{2}$ at a constant rate into the system and monitored the end-tidal carbon dioxide. We used a mechanical ventilator to deliver NIV in 8 different combinations of inspiratory effort, pressure support, and expiratory positive airway pressure. We measured end-tidal carbon dioxide mask leakage, tidal volume, trigger time, time to achieve $90 \%$ of the inspiratory target during inspiration, and excess inspiratory time. RESULTS: We presented the mean \pm SD of the 8 simulated conditions for each mask. The mean \pm SD leakage was higher for the total face mask $(51 \pm 6 \mathrm{~L} / \mathrm{min})$ than for the small oronasal mask $(37 \pm 5 \mathrm{~L} / \mathrm{min})$ and for the large oronasal mask $(21 \pm 3 \mathrm{~L} / \mathrm{min}), P<.001$; but end-tidal carbon dioxide and tidal volume were similar. The mean \pm SD $90 \%$ of the inspiratory target during inspiration was faster for the small oronasal mask $(585 \pm 49 \mathrm{~ms})$ compared with the large oronasal $(647 \pm 107 \mathrm{~ms})$ and total face mask $(851 \pm 105 \mathrm{~ms}), P<.001$, all other variables were similar. CONCLUSIONS: In this model, we found that the type of mask had no impact on $\mathrm{CO}_{2}$ washout or on most synchrony variables. Key words: artificial respiration; chronic obstructive pulmonary disease; masks; respiratory insufficiency; theoretical model. [Respir Care 2019;64(11):1416-1421. (C) 2019 Daedalus Enterprises]
\end{abstract}

\section{Introduction}

Noninvasive ventilation (NIV) decreases endotracheal intubation rates, length of hospital stay, mechanical ventilation complications, and mortality for specific populations, particularly in COPD. ${ }^{1,2}$ Recent clinical practice

Drs Rocha de Macedo, Diniz Silva, Valerio Pinaffi, and Carvalho Ferreira are affiliated with the Divisao de Pneumologia, Instituto do Coracao, Hospital das Clinicas HCFMUSP, Faculdade de Medicina, Universidade de Sao Paulo, Sao Paulo, Brazil. Dr Mambrini Pires Rego is affiliated with the Divisao de Anestesiologia, Hospital das Clinicas HCFMUSP, Faculdade de Medicina, Universidade de Sao Paulo, Sao Paulo, Brazil.

Dr Rocha de Macedo presented the abstract of this paper as a poster in the American Thoracic Society Conference held in San Diego, California, on May 18-23, 2018.

Dr Carvalho Ferreira discloses a relationship with Medtronics. The remaining authors have disclosed no conflicts of interest. guidelines recommend NIV as first-line ventilatory support to treat acute respiratory failure (ARF) in COPD, ${ }^{3-5}$ and its use has increased $462 \%$ in the United States from 1998 to $2008 .{ }^{6}$ Unfortunately, treatment intolerance causes $50-100 \%$ of NIV complications, can compromise the efficacy of NIV, ${ }^{7}$ and is associated with worse clinical outcomes. ${ }^{6}$ NIV failure can be related to the type and severity of respiratory failure, timing of NIV application in the course of the disease, patient factors, and the type of mask used. ${ }^{8}$ The mask used to deliver NIV can result in variable rates of air leaks, ${ }^{910} \mathrm{CO}_{2}$ rebreathing, tidal volume $\left(\mathrm{V}_{\mathrm{T}}\right)$, and patient-ventilator synchrony, all of which can increase

Correspondence: Bruno Rocha de Macedo MD, Instituto do Coracao, UTI Respiratoria, 8 andar Bloco 1, Av. Dr. Enéas Carvalho Aguiar 44, Sao Paulo, Brazil, CEP: 05403-000.E-mail: bruno.macedo@hc.fm.usp.br.

DOI: $10.4187 /$ respcare. 06746 
the work of breathing and lead to progressive respiratory failure. ${ }^{11-13}$

Historically, masks that cover the mouth, nose, or both have been used to treat ARF, 9,14 until masks that cover larger surfaces of the face were available, with similar efficiency and more comfort. ${ }^{15,16}$ These larger-volume total face masks reduce the respiratory rate, ${ }^{17}$ use of accessory muscles, and $\mathrm{P}_{\mathrm{CO}_{2}}{ }^{14,17}$ when compared with oronasal masks, without clear superiority in terms of clinical outcomes. ${ }^{14,17-19}$ However, clinical studies ${ }^{14,16-19}$ that compared NIV masks used different methods and outcomes, baring unmeasurable subjective factors related to patients and staff. Moreover, there is no consensus regarding an NIV mask choice in the ARF secondary to COPD exacerbations. Our aim was to compare air leaks, $\mathrm{CO}_{2}$ washout, and patient-ventilator synchrony across 3 different masks during NIV by using a lung model of hypercapnic exacerbation of COPD.

\section{Methods}

We conducted this study in the Mechanical Ventilation Laboratory in the Instituto do Coracao of the University of Sao Paulo Medical School, São Paulo, Brazil, after submission to the local research committee. We used a computerized lung simulator (ASL5000, Ingmar Medical, Pittsburgh, Pennsylvania), which consisted of a piston moving inside a cylinder (Fig. 1). We set the model's compliance, resistance, and inspiratory muscle pressure. ${ }^{20-22} \mathrm{We}$ simulated a COPD exacerbation by setting respiratory system compliance at $80 \mathrm{~mL} / \mathrm{cm} \mathrm{H}_{2} \mathrm{O}$, inspiratory resistance at $10 \mathrm{~cm} \mathrm{H}_{2} \mathrm{O} / \mathrm{L} / \mathrm{s}$, and end-tidal carbon dioxide $\left(\mathrm{ETCO}_{2}\right)$ expiratory resistance at $20 \mathrm{~cm} \mathrm{H}_{2} \mathrm{O} / \mathrm{L} / \mathrm{s}$. The respiratory

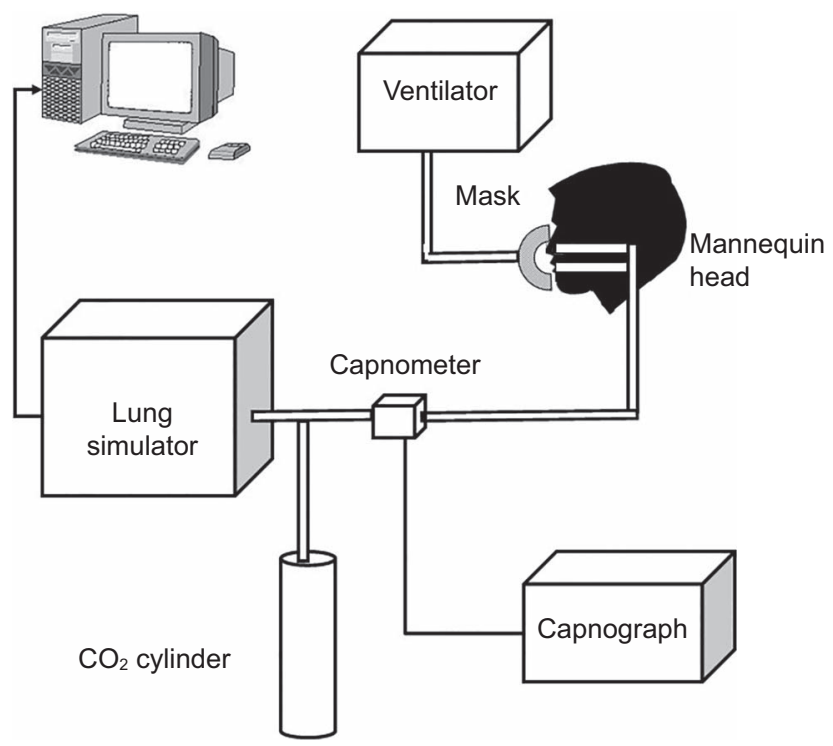

Fig. 1. Study setup.

\section{QUICK LOOK}

\section{Current knowledge}

Noninvasive ventilation is the mainstay treatment for acute respiratory failure in COPD, and the type of mask used may affect treatment efficacy. Many clinical factors, individual mask tolerance, and team expertise also influence noninvasive ventilation success. There are no guidelines on how to choose an adequate mask for treatment.

\section{What this paper contributes to our knowledge}

An experimental model eliminated subjective factors related to noninvasive ventilation tolerance. In this experimental lung model of COPD exacerbation, we found that the mask type did not affect tidal volume, end-tidal carbon dioxide, and most of the synchrony variables.

rate was 15 breaths $/ \mathrm{min}$, and inspiratory time was $0.80 \mathrm{~s}$. We set inspiratory muscle pressure to $-3 \mathrm{~cm} \mathrm{H}_{2} \mathrm{O}$ or $-5 \mathrm{~cm} \mathrm{H}_{2} \mathrm{O}$, and set expiratory muscle pressure to $+2 \mathrm{~cm}$ $\mathrm{H}_{2} \mathrm{O}$ (Fig. 2).

We connected the tested masks to a fiberglass mannequin head with endotracheal tubes directing the air flow from within the mouth and nose to the lung simulator. The masks were connected tightly to the mannequin's face by using the straps provided by the manufacturer to minimize leaks. We tested 3 models of masks: a small oronasal mask (Comfort Full, Philips, size L, internal volume $260 \mathrm{~mL}$, Philips, Andover, Massachusetts), which covers the mouth and nose; a total face mask (Totalface, size S, internal volume 1,500 $\mathrm{mL}$, Philips), which covers a larger surface of the face; and a large oronasal mask (Performax, size L, internal volume $550 \mathrm{~mL}$, Philips) (Fig. 3).

To simulate hypercapnic respiratory failure, we added $\mathrm{CO}_{2}$ at $100 \%$ to the system with a flow regulator titrated to obtain a constant $\mathrm{ETCO}_{2}$ of $7 \mathrm{~mm} \mathrm{Hg}$ measured by volumetric capnography $\left(\mathrm{NICO}_{2}\right.$, Philips) at baseline without inspiratory support as described in other models. ${ }^{23} \mathrm{We}$ connected a mechanical ventilator (Vision, Philips) with a single-limb circuit (Philips) to deliver NIV in spontaneous/timed mode with a backup respiratory rate of 4 breaths/min and inspiratory pressure above expiratory positive airway pressure (EPAP) of either 3 or $5 \mathrm{~cm} \mathrm{H}_{2} \mathrm{O}$ and EPAP of either 5 or $8 \mathrm{~cm} \mathrm{H}_{2} \mathrm{O}$. To apply such pressures, the ventilator was set to deliver EPAP $=5 \mathrm{~cm} \mathrm{H}_{2} \mathrm{O}$ and inspiratory positive airway pressure (IPAP) $=8 \mathrm{~cm} \mathrm{H}_{2} \mathrm{O}$ (inspiratory pressure above EPAP of $3 \mathrm{~cm} \mathrm{H}_{2} \mathrm{O}$ ), EPAP $=5 \mathrm{~cm} \mathrm{H}_{2} \mathrm{O}$ and IPAP $=10 \mathrm{~cm} \mathrm{H}_{2} \mathrm{O}$ (inspiratory pressure above EPAP of $5 \mathrm{~cm} \mathrm{H}_{2} \mathrm{O}$ ), EPAP $=8 \mathrm{~cm} \mathrm{H}_{2} \mathrm{O}$ and IPAP $=11 \mathrm{~cm} \mathrm{H}_{2} \mathrm{O}$ (inspiratory pressure above EPAP of $3 \mathrm{~cm} \mathrm{H}_{2} \mathrm{O}$ ), or EPAP $=8 \mathrm{~cm} \mathrm{H}_{2} \mathrm{O}$ and IPAP $=13 \mathrm{~cm} \mathrm{H}_{2} \mathrm{O}$ 
(inspiratory pressure above EPAP of $5 \mathrm{~cm} \mathrm{H}_{2} \mathrm{O}$ ). We randomized the sequence of application of the 8 combinations of inspiratory pressure, EPAP, and inspiratory effort for each mask and waited at least 5 min for stabilization before recording 20 cycles of each of the 8 conditions.

We recorded the air-leak rate shown on the ventilator screen, and the $\mathrm{ETCO}_{2}$ was measured by the $\mathrm{NICO}_{2}$ monitor for each condition. The lung simulator recorded pressure, volume, and flow at $512 \mathrm{~Hz}$, and provided breathby-breath $\mathrm{V}_{\mathrm{T}}$ actually delivered to the model (not including the volume that leaked) and synchrony parameters (Fig. 4). To obtain the mean values for each condition and type of mask, we performed offline analysis of cycles with the lung simulator software (LabView, National Instruments, Austin, Texas) after removing cycles with artifacts. Values are expressed as mean $\pm \mathrm{SD}$. We used analysis of variance for repeated measures to compare the 3 types of masks and the Bonferroni test for post hoc comparisons. We used SPSS 13.0 (SPSS, Chicago, Illinois), and considered $P$ values $<.05$ as statistically significant.

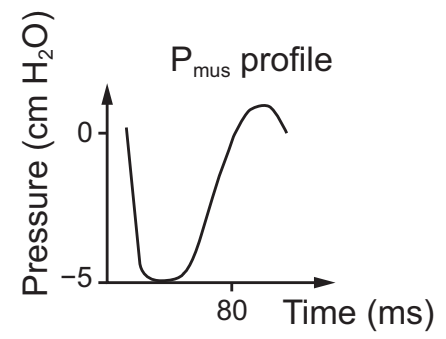

Fig. 2. Inspiratory muscle pressure $\left(P_{\text {mus }}\right)$ over time. The $P_{\text {mus }}$ waveform was created by using the computerized lung simulator and set to $-5 \mathrm{~cm} \mathrm{H}_{2} \mathrm{O}$ (as shown) or $-3 \mathrm{~cm} \mathrm{H}_{2} \mathrm{O}$.

\section{Results}

Air leak was higher for the total face mask than for the small oronasal mask and large oronasal mask (Fig. 5). The $\mathrm{ETCO}_{2}$ was similar for the 3 masks (Fig. 6). $\mathrm{V}_{\mathrm{T}}$ and synchrony variables are presented in Table 1 . The 3 masks yielded similar $\mathrm{V}_{\mathrm{T}}$. The time to achieve $90 \%$ of the inspiratory target during inspiration was shorter in the small oronasal mask than in the large oronasal and total face masks. Triggering variables (trigger time, trigger pressure, baseline pressure during triggering) did not show statistical difference. We also did not observe differences among the types of mask and cycling performance, measured with delayed cycling.

\section{Discussion}

We analyzed objective parameters of NIV masks in a lung model that simulated ARF secondary to COPD exacerbation ventilated with 3 types of mask and 8 combinations of NIV settings. We found higher air leaks with the total face mask compared with the 2 other masks and no significant differences in $\mathrm{V}_{\mathrm{T}}$ and $\mathrm{ETCO}_{2}$. Inspiratory pressurization time, measured with the time to achieve $90 \%$ of the inspiratory target during inspiration, was significantly faster for the small oronasal mask compared with the total face mask and large oronasal mask, but all other synchrony variables were similar across the 3 types of masks.

\section{Mask Selection}

The use of the oronasal mask is recommended over nasal masks ${ }^{24}$ for patients who are critically ill and in $\mathrm{ARF}$, but there are no recommendations for when to choose oronasal or total face masks. Results of a survey found that
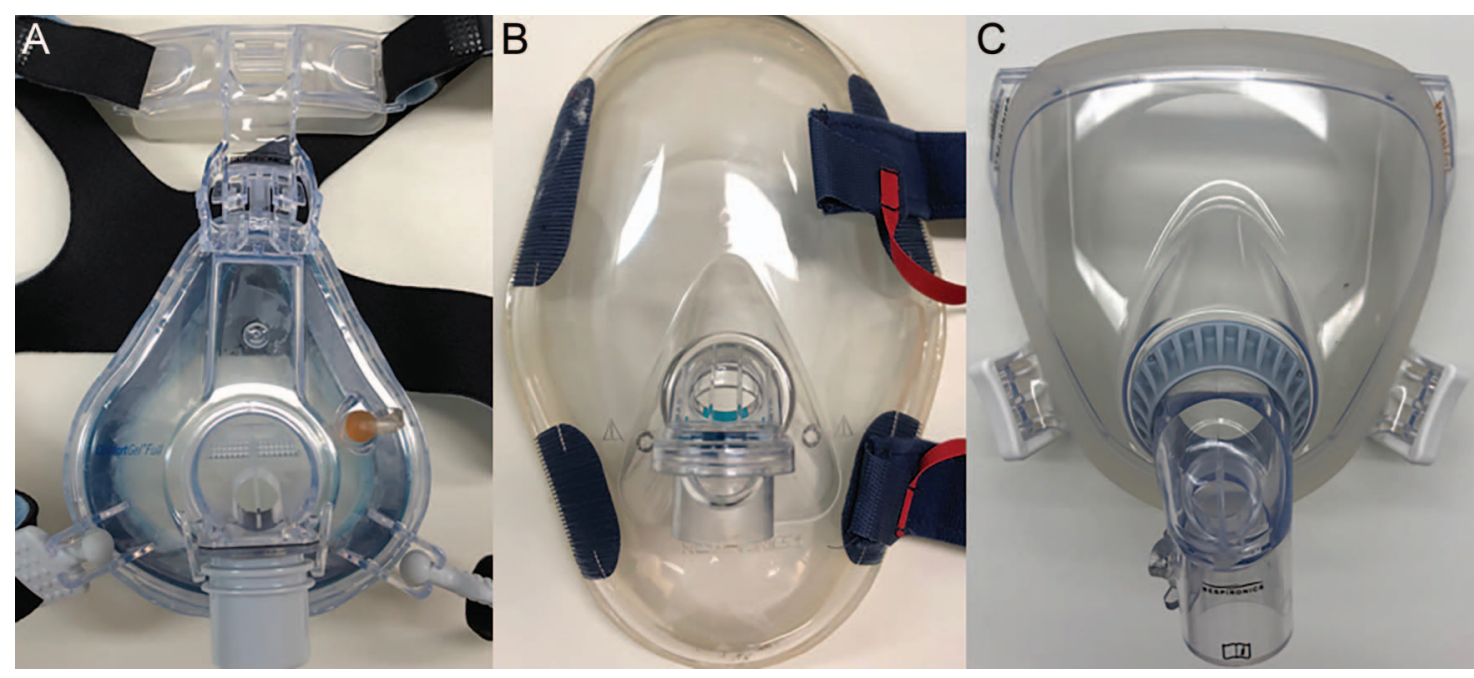

Fig. 3. A: Small oronasal mask (Comfort Full), B: total face mask (Totalface), and C: large oronasal mask (Performax). 


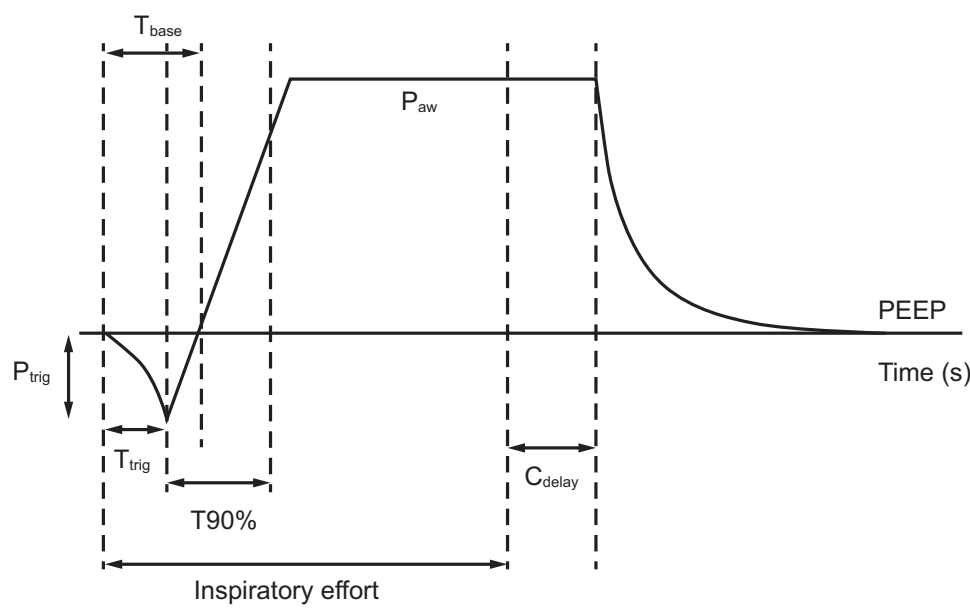

Fig. 4. Variables obtained from the lung simulator. Trigger time $\left(T_{\text {trig }}\right)$ in ms, time between the start of the triggering effort and to its completion; Trigger pressure $\left(\mathrm{P}_{\text {trig }}\right)$ in $\mathrm{cm} \mathrm{H}_{2} \mathrm{O}$, pressure that triggers the inspiratory cycle; time to return to baseline pressure during triggering $\left(T_{\text {base }}\right)$ in ms; time to achieve $90 \%$ of the inspiratory target during inspiration in ms; and delayed cycling $\left(\mathrm{C}_{\text {delay }}\right)$, which is the difference between the mechanical inspiratory time and the neural time (set to $0.80 \mathrm{~s}$ ) in ms.

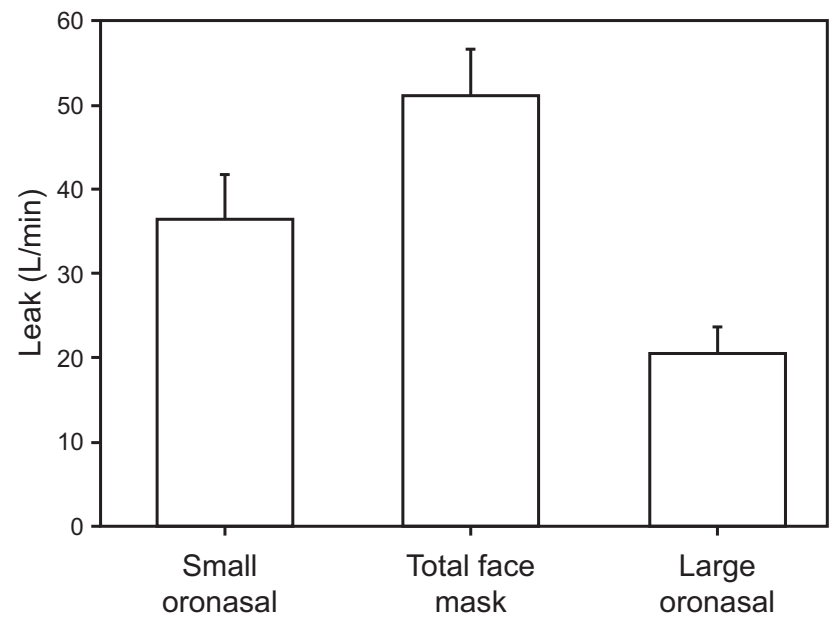

Fig. 5. Mean air leak for the small oronasal mask, total face mask, and large oronasal mask. Air leak was significantly higher for the total face mask than for the small oronasal mask and large oronasal mask $(P<.001$ for both comparisons with the Bonferroni correction) and higher for the small oronasal mask than for the large oronasal mask $(P<$.001). Error bars represent SDs.

patient comfort, prevention of air leaks, and cost determines mask choice. ${ }^{9}$ Results of randomized controlled trials indicated similar tolerance to both oronasal and total face mask in $\mathrm{ARF}^{18,19}$ and specifically in ARF with hypercapnia. ${ }^{18}$ Results of a randomized controlled trial indicated improvement in tolerance to the oronasal mask after $24 \mathrm{~h}$ of use compared with the total face mask. ${ }^{18}$ The oronasal mask is the most widely used, and there is a suggested "rotating" strategy, which consists of switching the type of mask from time to time. ${ }^{8}$ It is unlikely that any one mask will prove to be optimum for all NIV applications $^{25}$ but it is clear that patient compliance, and, there-

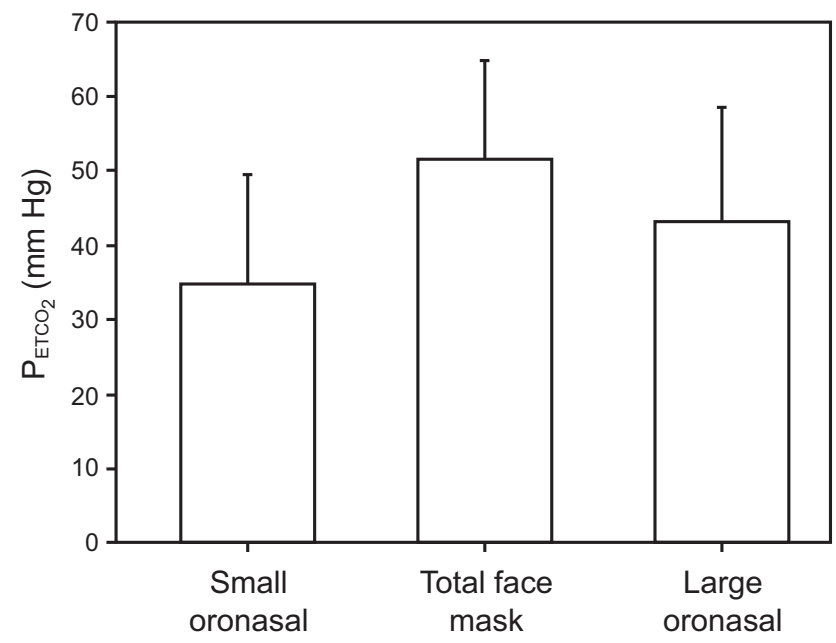

Fig. 6. Mean end-tidal carbon dioxide pressure $\left(\mathrm{P}_{\mathrm{ETCO}_{2}}\right)$ for the small oronasal mask, total face mask, and large oronasal mask. There was no significant difference among the masks $(P=.09$ for the analysis of variance). Error bars represent SDs.

fore, NIV success, is greatly dependent on the type of mask. ${ }^{26,27}$

\section{Air Leaks}

We found that air leaks were associated with the internal volume and the surface of the mask. Other investigators used a pneumotachograph to measure pressure and flow in the circuit and mask to estimate air leaks and its compensation by the ventilator ${ }^{11}$ or to measure the pressure in the pneumatic cushion of the mask to optimize air leaks. ${ }^{28}$ However, in our study, air leaks were not associated with different $\mathrm{V}_{\mathrm{T}}$ or $\mathrm{ETCO}_{2}$. These findings were in line with a prospective randomized trial with 14 subjects 


\section{NIV Mask Performance in COPD}

Table 1. $\quad \mathrm{V}_{\mathrm{T}}$ and Synchrony Variables for the Three Types of Masks

\begin{tabular}{|c|c|c|c|}
\hline & $\begin{array}{l}\text { Small } \\
\text { Oronasal } \\
\text { Mask }\end{array}$ & $\begin{array}{l}\text { Total } \\
\text { Face } \\
\text { Mask }\end{array}$ & $\begin{array}{l}\text { Large } \\
\text { Oronasal } \\
\text { Mask }\end{array}$ \\
\hline $\mathrm{V}_{\mathrm{T}}, \mathrm{mL}$ & $213 \pm 40$ & $193 \pm 38$ & $205 \pm 37$ \\
\hline $\mathrm{T}_{\text {trig }}, \mathrm{ms}$ & $137 \pm 36$ & $154 \pm 22$ & $140 \pm 25$ \\
\hline $\mathrm{P}_{\text {trig }}, \mathrm{cm} \mathrm{H}_{2} \mathrm{O}$ & $0.57 \pm 0.12$ & $0.7 \pm 0.18$ & $0.56 \pm 0.13$ \\
\hline $\mathrm{InspT}_{90}, \mathrm{~ms}$ & $585 \pm 49^{*}$ & $851 \pm 105$ & $647 \pm 107$ \\
\hline $\mathrm{T}_{\text {base }}, \mathrm{ms}$ & $237 \pm 39$ & $264 \pm 45$ & $255 \pm 55$ \\
\hline $\mathrm{C}_{\text {delay }}, \mathrm{ms}$ & $47 \pm 41$ & $36 \pm 40$ & $44 \pm 39$ \\
\hline \multicolumn{4}{|c|}{$\begin{array}{l}\text { Values are expressed as mean } \pm \mathrm{SD} \text {. } \\
\text { * Insp } \mathrm{T}_{90} \text { was significantly shorter in the small oronasal mask than in the large oronasal and } \\
\text { total face masks, } P=.01 \text { for both comparisons with the Bonferroni correction. } \\
\mathrm{V}_{\mathrm{T}}=\text { tidal volume } \\
\mathrm{T}_{\text {trig }}=\text { trigger time (time between the start of the triggering effort to its completion) } \\
\mathrm{P}_{\text {trig }}=\text { trigger pressure (pressure required to trigger the inspiratory cycle) } \\
\text { Insp } \mathrm{T}_{90}=\text { time to achieve } 90 \% \text { of the inspiratory target during inspiration } \\
\mathrm{T}_{\text {base }}=\text { time to return to baseline pressure during triggering } \\
\mathrm{C}_{\text {delay }}=\text { delayed cycling (the difference between the mechanical inspiratory time and the } \\
\text { neural time) }\end{array}$} \\
\hline
\end{tabular}

in ARF due to exacerbation of COPD that compared a nasal mask and a oronasal mask, which found that neither dead space nor differences in air leaks affected $\mathrm{P}_{\mathrm{CO}_{2} \cdot{ }^{17}}$ Air leaks are a characteristic feature of NIV, and ventilators are designed to compensate for this, but compensation of a high rate of air leaks does not avoid patient-ventilator asynchrony. ${ }^{29}$ Previous investigators have indicated that air leaks can extend trigger, decrease inspiratory pressurization, delay cycling, ${ }^{30}$ and induce autotriggering. ${ }^{29} \mathrm{We}$ found an association between higher air leaks and slower inspiratory pressurization, but no association with triggering or cycling delays.

\section{$\mathrm{CO}_{2}$ Washout}

We found that $\mathrm{ETCO}_{2}$ was reduced from baseline for the 3 masks, as expected, without any significant differences between the masks. $\mathrm{CO}_{2}$ washout is one of the objectives of NIV in ARF due to COPD exacerbations. ${ }^{23}$ Some degree of rebreathing of $\mathrm{CO}_{2}$ is inevitable but excessive rebreathing may negatively impact NIV efficiency because $\mathrm{ETCO}_{2}$ increases of as little as $4 \mathrm{~mm} \mathrm{Hg}$ can lead to air hunger and higher breathing frequencies. ${ }^{31}$ Our results contrasted with those of a clinical trial, which included 48 subjects with ARF and hypercapnia in which the oronasal mask led to greater $\mathrm{P}_{\mathrm{CO}_{2}}$ reduction than the total face mask. ${ }^{14}$ The disparity was probably related to the fact that we used an experimental model and that $\mathrm{ETCO}_{2}$ may underestimate $\mathrm{P}_{\mathrm{CO}_{2}}{ }^{26}$

\section{Synchrony}

Patient-ventilator asynchrony can decrease NIV tolerance, ${ }^{9}$ contribute to NIV failure, ${ }^{32}$ and worsen clinical outcomes. ${ }^{33}$ Asynchrony indexes of $>10 \%$ have been reported in as many as $43 \%$ of patients on NIV. ${ }^{12}$ COPD is a risk factor for asynchrony in particular because of the presence of auto-PEEP. ${ }^{12,27,34} \mathrm{We}$ found that the time to achieve $90 \%$ of the inspiratory target during inspiration was faster for the oronasal mask, but all other patient-ventilator synchrony variables were comparable for the 3 masks. The mean trigger delay and cycling delay in ms were relatively short in our study, possibly because our model did not include hyperinflation and auto-PEEP.

\section{Limitations}

We had several limitations in this study. First, we used a lung simulator, which lost the biologic variability of respiratory rate and lung mechanics. The simulator also did not simulate ventilation-perfusion mismatches that typically occur in patients with COPD and that contributes to $\mathrm{CO}_{2}$ retention. However, using a lung simulator allows for an objective comparison of the masks under identical experimental conditions because the model does not move or worsen clinically; therefore, it offers a measure of objective performance of the masks under controlled conditions, which needs to be confirmed later in patients. Second, $\mathrm{CO}_{2}$ flow that mimics $\mathrm{CO}_{2}$ production was constant during the experiment as opposed to real-life situations. In addition, our measurement of air leaks relied on the ventilator's estimation and may not be accurate. To minimize this caveat, we connected all the masks very tightly to the fiberglass mannequin head to minimize leaks around the mask. Third, we could not evaluate dynamic changes in mask fitting because patients breath and move, which can be challenging in real-life patients. However, the absence of dynamic change in leak volume provides an objective measurement of the performance of the masks under each ventilatory condition. Fourth, we only tested 3 models of masks and 1 ventilator, whereas many more are available in clinical use, and, therefore, our results may not be generalizable in different conditions.

\section{Conclusions}

We found that, under controlled experimental conditions by using a lung simulator, the type of mask did not affect $\mathrm{V}_{\mathrm{T}}, \mathrm{ETCO}_{2}$, and synchrony variables, and, therefore, it may not have a major impact on NIV success. Clinical studies that focus on monitoring patient's response and tolerance to different types of masks are needed to better describe the influence of the interface on NIV success and guide clinicians who care for patients who are critically ill. 


\section{NIV Mask Performance in COPD}

\section{ACKNOWLEDGMENTS}

The authors thank the Methods in Epidemiologic, Clinical and Operations Research Program, the American Thoracic Society, and Asociación Latinomericana de Tórax, for their support and dedication in building research capacity in Latin America and other countries around the globe.

\section{REFERENCES}

1. Brochard L, Mancebo J, Wysocki M, Lofaso F, Conti G, Rauss A, et al. Noninvasive ventilation for acute exacerbations of chronic obstructive pulmonary disease. N Engl J Med 1995;333(13):817822.

2. Osadnik CR, Tee VS, Carson-Chahhoud KV, Picot J, Wedzicha JA, Smith BJ. Non-invasive ventilation for the management of acute hypercapnic respiratory failure due to exacerbation of chronic obstructive pulmonary disease. Cochrane Database Syst Rev 2017;7: CD004104.

3. Rochwerg B, Brochard L, Elliott MW, Hess D, Hill NS, Nava S, et al.; Navalesi P Members of the Steering Committee; Raoof $S$ Members of the Task Force. Official ERS/ATS clinical practice guidelines: noninvasive ventilation for acute respiratory failure. Eur Respir J 2017;50(2). pii:1602426.

4. Barbas CS, Isola AM, Farias AM, Cavalcanti AB, Gama AMC, Duarte ACM, et al. Brazilian recommendations of mechanical ventilation 2013. Part I. Rev Bras Ter Intensiva 2014;26(2):89-121.

5. Garpestad E, Brennan J, Hill NS. Noninvasive ventilation for critical care. Chest 2007;132(2):711-720.

6. Chandra D, Stamm JA, Taylor B, Ramos RM, Satterwhite L, Krishnan JA, et al. Outcomes of noninvasive ventilation for acute exacerbations of chronic obstructive pulmonary disease in the United States, 1998-2008. Am J Respir Crit Care Med 2012;185(2):152159.

7. Holanda MA, Reis RC, Winkeler GF, Fortaleza SC, Lima JW, Pereira ED. Influence of total face, facial and nasal masks on short-term adverse effects during noninvasive ventilation. J Bras Pneumol 2009; 35(2):164-173.

8. Ozyilmaz E, Ugurlu AO, Nava S. Timing of noninvasive ventilation failure: causes, risk factors, and potential remedies. BMC Pulm Med 2014;14:19.

9. Pisani L, Carlucci A, Nava S. Interfaces for noninvasive mechanical ventilation: technical aspects and efficiency. Minerva Anestesiol 2012;78(10):1154-1161.

10. Nava S. Behind a mask: tricks, pitfalls, and prejudices for noninvasive ventilation. Respir Care 2013;58(8):1367-1376.

11. Nakamura MA, Costa EL, Carvalho CR, Tucci MR. Performance of ICU ventilators during noninvasive ventilation with large leaks in a total face mask: a bench study. J Bras Pneumol 2014;40(3):294-303.

12. Vignaux L, Vargas F, Roeseler J, Tassaux D, Thille AW, Kossowsky MP, et al. Patient-ventilator asynchrony during non-invasive ventilation for acute respiratory failure: a multicenter study. Intensive Care Med 2009;35(5):840-846.

13. Kacmarek RM. Noninvasive positive-pressure ventilation: the little things do make the difference! Respir Care 2003;48(10):919-921.

14. Sadeghi S, Fakharian A, Nasri P, Kiani A. Comparison of comfort and effectiveness of total face mask and oronasal mask in noninvasive positive pressure ventilation in patients with acute respiratory failure: a clinical trial. Can Respir J 2017;2017:2048032.

15. Keenan SP, Winston B. Interfaces for noninvasive ventilation: does it matter? J Bras Pneumol 2009;35(2):103-105.

16. Navalesi P, Fanfulla F, Frigerio P, Gregoretti C, Nava S. Physiologic evaluation of noninvasive mechanical ventilation delivered with three types of masks in patients with chronic hypercapnic respiratory failure. Crit Care Med 2000;28(6):1785-1790.

17. Antón A, Tárrega J, Giner J, Güell R, Sanchis J. Acute physiologic effects of nasal and full-face masks during noninvasive positivepressure ventilation in patients with acute exacerbations of chronic obstructive pulmonary disease. Respir Care 2003;48(10):922-925.

18. Cuvelier A, Pujol W, Pramil S, Molano LC, Viacroze C, Muir JF. Cephalic versus oronasal mask for noninvasive ventilation in acute hypercapnic respiratory failure. Intensive Care Med 2008;35(3):519526.

19. Ozsancak A, Sidhom SS, Liesching TN, Howard W, Hill NS. Evaluation of the total face mask for noninvasive ventilation to treat acute respiratory failure. Chest 2011;139(5):1034-1041.

20. Ferreira JC, Chipman DW, Hill NS, Kacmarek RM. Bilevel vs ICU ventilators providing noninvasive ventilation: effect of system leaks: a COPD lung model comparison. Chest 2009;136(2):448-456.

21. Ferreira JC, Chipman DW, Kacmarek RM. Trigger performance of mid-level ICU mechanical ventilators during assisted ventilation: a bench study. Intensive Care Med 2008;34(9):1669-1675.

22. Macedo BR, Diniz Silva F, Pinaffi JV, Rego FMP, Ferreira JC. Influence of non-invasive ventilation mask on $\mathrm{CO} 2$ washout and synchrony in a lung model simulating chronic obstructive pulmonary disease and hypercapnia (abstract). Am J Respir Crit Care Med 2018;197:A5096.

23. Schettino GP, Chatmongkolchart S, Hess DR, Kacmarek RM. Position of exhalation port and mask design affect $\mathrm{CO} 2$ rebreathing during noninvasive positive pressure ventilation. Crit Care Med 2003; 31(8):2178-2182.

24. Keenan SP, Sinuff T, Burns KE, Muscedere J, Kutsogiannis J, Mehta S, et al.; Canadian Critical Care Trials Group/Canadian Critical Care Society Noninvasive Ventilation Guidelines Group. Clinical practice guidelines for the use of noninvasive positive-pressure ventilation and noninvasive continuous positive airway pressure in the acute care setting. CMAJ 2011;183(3):E195-E214.

25. Hill NS. Saving face: better interfaces for noninvasive ventilation. Intensive Care Med 2002;28(3):227-229.

26. Ergan B, Nasiłowski J, Winck JC. How should we monitor patients with acute respiratory failure treated with noninvasive ventilation? Eur Respir Rev 2018;27(148). pii:170101.

27. Mas A, Masip J. Noninvasive ventilation in acute respiratory failure. Int J Chron Obstruct Pulmon Dis 2014;9:837-852.

28. Schettino GP, Tucci MR, Sousa R, Valente Barbas CS, Passos Amato MB, Carvalho CR. Mask mechanics and leak dynamics during noninvasive pressure support ventilation: a bench study. Intensive Care Med 2001;27(12):1887-1891.

29. Carteaux G, Lyazidi A, Cordoba-Izquierdo A, Vignaux L, Jolliet P, Thille AW, et al. Patient-ventilator asynchrony during noninvasive ventilation: a bench and clinical study. Chest 2012;142(2):367-376.

30. Stell IM, Paul G, Lee KC, Ponte J, Moxham J. Noninvasive ventilator triggering in chronic obstructive pulmonary disease. A test lung comparison. Am J Respir Crit Care Med 2001;164(11):2092-2097.

31. Szkulmowski Z, Belkhouja K, Le QH, Robert D, Argaud L. Bilevel positive airway pressure ventilation: factors influencing carbon dioxide rebreathing. Intensive Care Med 2010;36(4):688-691.

32. Scala R, Pisani L. Noninvasive ventilation in acute respiratory failure: which recipe for success? Eur Respir Rev 2018;27(149). pii: 180029.

33. Holanda MA, Vasconcelos RDS, Ferreira JC, Pinheiro BV. Patientventilator asynchrony. J Bras Pneumol 2018;44(4):321-333.

34. Nava S, Bruschi C, Rubini F, Palo A, Iotti G, Braschi A. Respiratory response and inspiratory effort during pressure support ventilation in COPD patients. Intensive Care Med 1995;21(11):871-879. 